\title{
Rare Oral Mucous Extravasation Cyst: Case Report
}

\author{
Rajae El Gaouzi ${ }^{*}$, Bassima Chami ${ }^{2}$ \\ ${ }^{1}$ Oral Surgery Department, Faculty of Dentistry, Mohammed V University, Rabat 6212, Morocco \\ ${ }^{2}$ Oral Surgery Department, Faculty of Dentistry, Mohammed V University, Rabat 6212, Morocco \\ *Corresponding author: Rajae El Gaouzi; rajae_elgaouzi@um5.ac.ma
}

Received 13 March 2021; $\quad$ Accepted 28 April 2021;

Published 10 April 2021

\begin{abstract}
Mucoceles are a benign lesions characterized by an extravasation or retention of mucous in submucosal tissue from minor salivary glands caused most probably by a trauma or habit of lip biting. They usually present as an asymptomatic small superficial swelling, which are knew to occur most commonly on the lower lip, followed by the floor of mouth and in other sites. However, uncommon variants of oral mucoceles sometimes occur. Such lesions may be difficult to diagnose due to their unusual localization and atypical clinical presentation. This paper highlights a rare case of mucocele localized in hard palate in a 63 years old male patient. The lesion was depressed, with a bluish appearance, and it measured 7 $\mathrm{mm} \times 5 \mathrm{~mm} \times 2 \mathrm{~mm}$. Diagnosis is based on clinical characteristics, and confirmed with histological features.
\end{abstract}

Keywords: Mucocele, hard palate lesion, extravasation cyst, benign lesion, surgical excision

\section{Introduction}

Mucocele is the most common lesion of the oral mucosa, it results from the accumulation of mucous secretion due to trauma and lip biting habits or alteration of minor salivary glands that causes limited swelling, characterized by a rounded, well-circumscribed, transparent, and bluish colored lesion of variable size ${ }^{[1]}$.

Mostly they are soft in consistency and fluctuate on palpation. Mucocele is painless and have a tendency to relapse ${ }^{[2]}$. The aim of this work was to present a patient who has been diagnosed to have a hard palate mucocele, and to evaluate the outcome of the surgical excision of this lesion.

\section{Case report}

A systemically healthy 63-years-old man was referred to department of oral surgery of Ibn Sina dental consultation and treatment center in Rabat, Morocco, with chief complaint of localized swelling on the hard palate mucosa since three months. He reported a history of mucosal trauma caused by a fishbone. Intraoral examination revealed a painless swelling with light bluish hue on the posterior of hard palate, about $7 \mathrm{~mm} \times 5 \mathrm{~mm} \times 2 \mathrm{~mm}$ in diameter, soft and fluctuant on palpation (Figure 1).

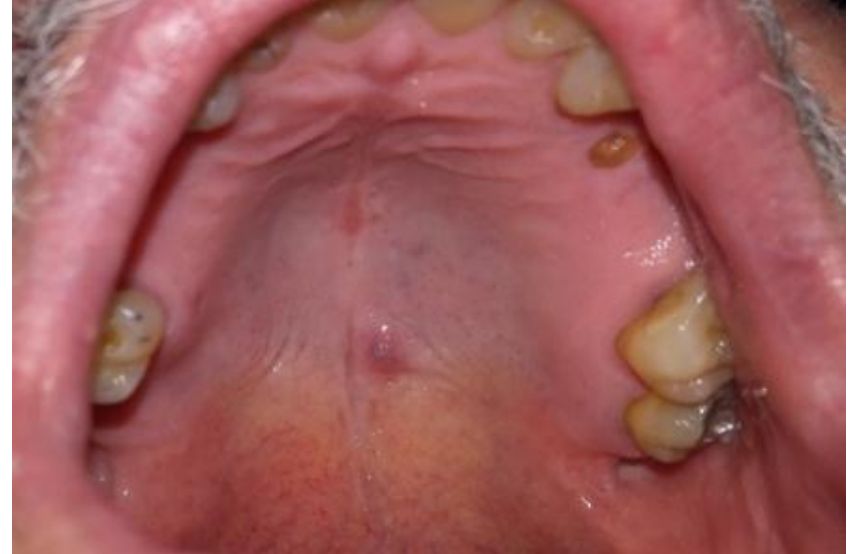

Figure 1: Pre-operative view of the lesion

Based on clinical apperances, provisional diagnosis of mucocele cyst and angioma was made. Excision of the lesion was planned under local anaesthesia, also a diode laser was planned to use in these cases to provide bloodless field. The lesion was anaesthetized with articaine $68 \mathrm{mg} / 1.7 \mathrm{ml}$ with 1/200 000 adrenaline. Aspiration test was made using a syringe $20 \mathrm{cc}$, resulting in release of viscous yellowish liquid. Then the complete excision was done (figure 2), and a few fine non-absorbable sutures were placed (figure 3 ), the bleeding was stopped without using diode laser. 


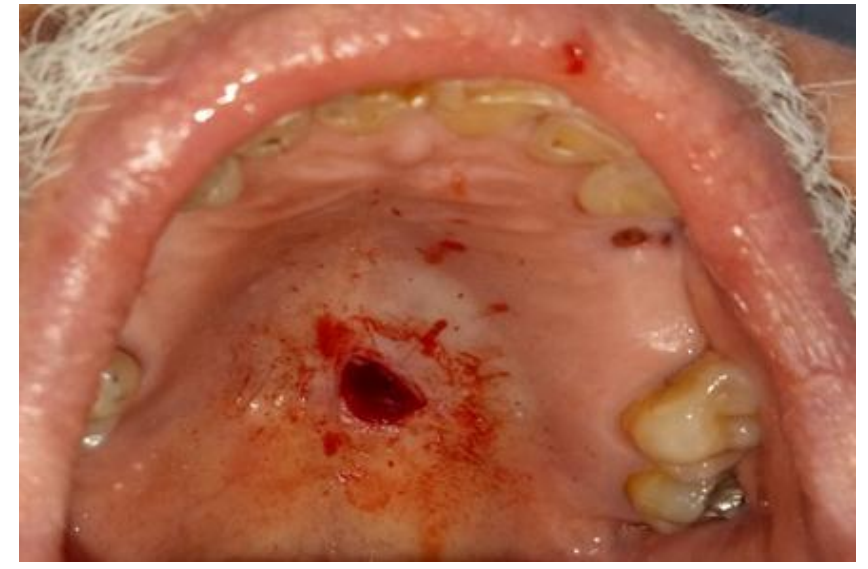

Figure 2: After excision of the lesion with safety margin

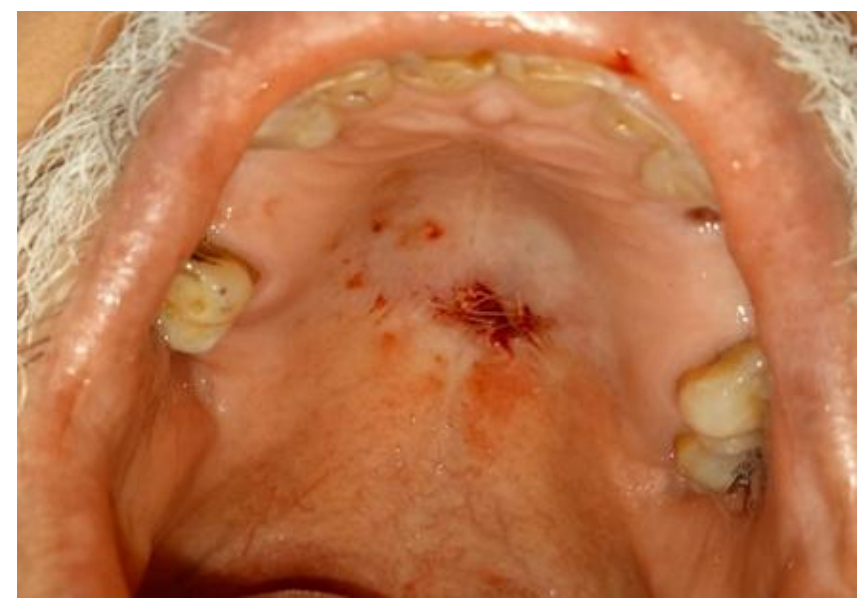

Figure 3: After making non resorbable sutures

A palate dental tray was used to protect the area during eating and swallowing. (Figure 4).

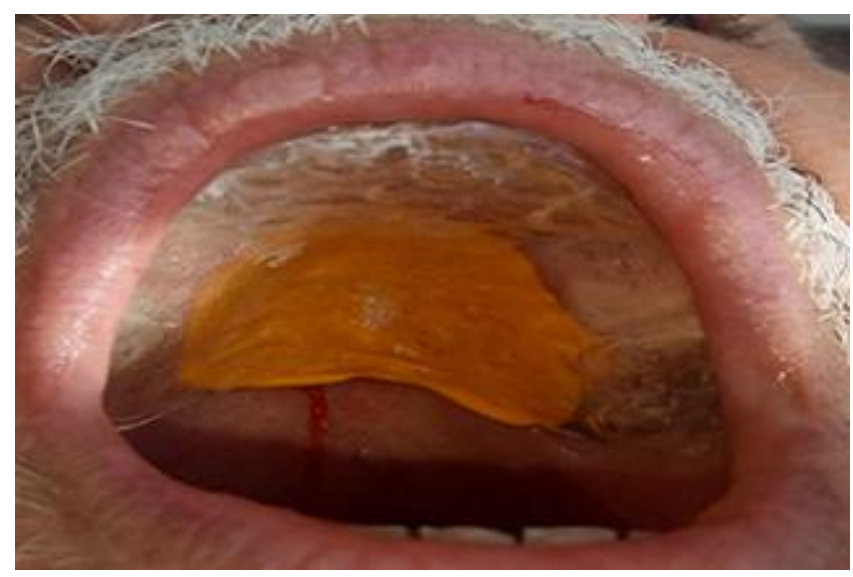

Figure 4: Palate dental tray

The tissue (figure 5) was conserved in Formol 10\% and sent for histopathologic investigation which revealed a stratified squamous mucosal lining, surmounted by a thin layer of parakeratinized cells corresponding to mucus extravasation cysts (figure $\neg 6-7$ ).

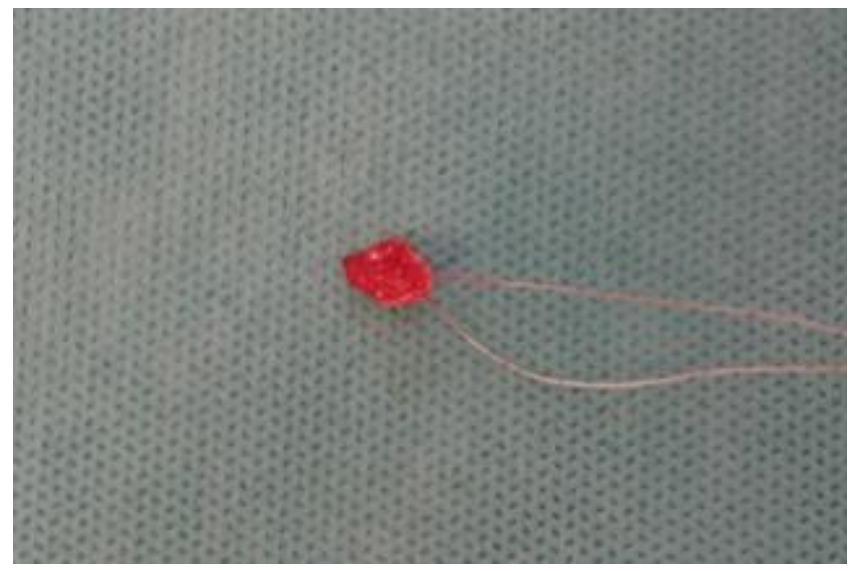

Figure 5: The surgical specimen

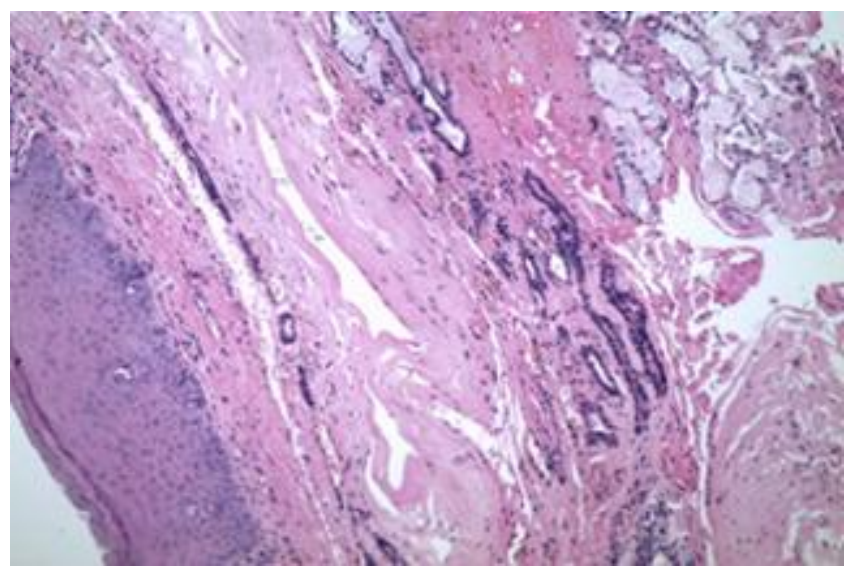

Figure 6: HES Stain G x 100 - Small cystic formation collapsed between the salivary glands.

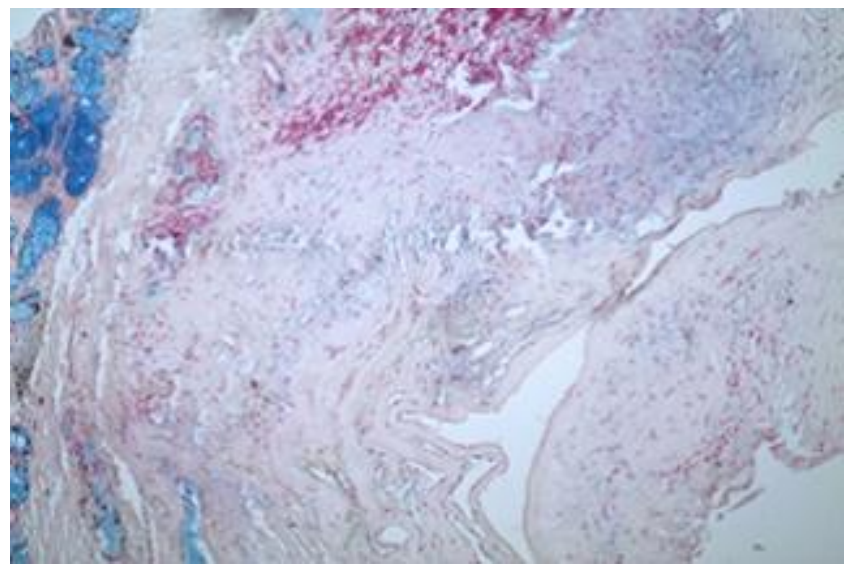

Figure 7: Alcian Blue stain G x 100 - Extravasation of alkanophilic mucin in the interstitium near the cyst.

The removal of the sutures was done at the 7 th day after the surgery (figure 8 ). The cyst was completely healed one month later (figure 9). 


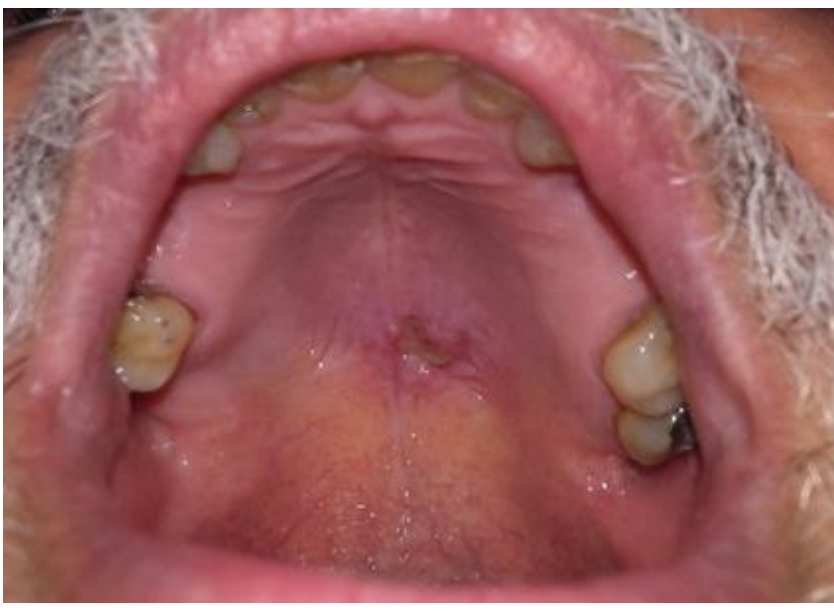

Figure 8: Postoperative view: Healing after one week

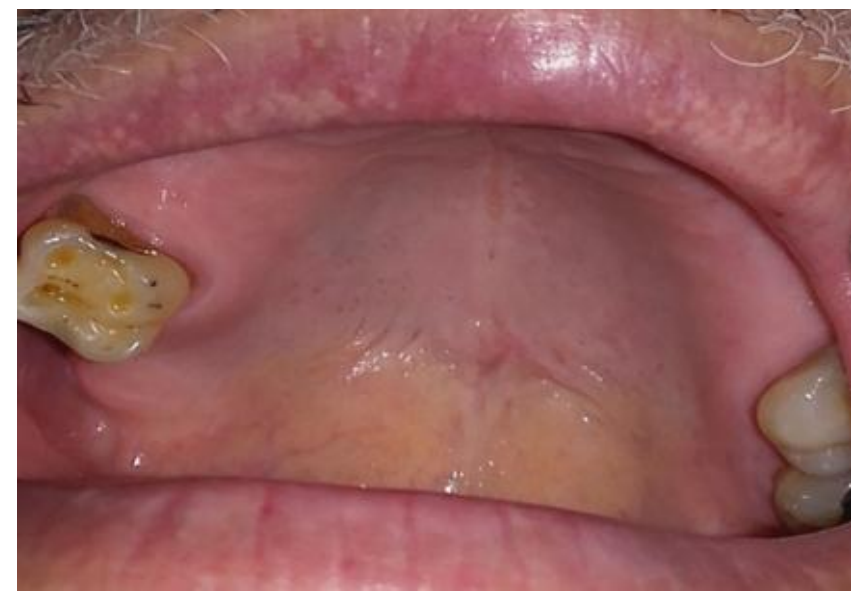

Figure 9: Follow up after one month and complete healing

\section{Discussion}

Mucoceles are mucus containing cystic lesions of the minor salivary glands, they are the 15th common oral mucosal lesion with a prevalence of 2.4 cases per 1000 people. Mucoceles occurs in young individuals, with $70 \%$ of them being younger than 20 years. Ranulas are mucoceles that occur in the floor of the mouth and usually involve the major salivary glands ${ }^{[3]}$.

Mucocele are mostly subdivided into two categories: Mucus extravasation type (90\%), and mucus retention type (10\%) [4].

The rupture of salivary gland's duct causes the first one because of injury that can lead to leakage and concentration of saliva in the surrounding tissues. In this way, a cavity is formed within the soft tissues, not surrounded by epithelial wall lining, developing a pseudocyst. The second one is caused by obstruction of the salivary duct leading to a true cyst covered by epithelium ${ }^{[4]}$.

The histological difference between extravasation and retention cyst is that the extravasation type has no epithelial lining and is formed by a mucus pool surrounded by granulation tissue and the retention cyst has an epithelial lining like this case reported [3].

Superficial mucoceles tend to occur in individuals older than 30 years ${ }^{[3]}$. According to some studies in the literature, there is no difference in the incidence of oral mucoceles between genders ${ }^{[5,6]}$. Lower lip is the most common site of occurrence, followed by tongue, floor of mouth (ranula), and the others oral mucosa sites ${ }^{[4]}$. Hard palate is a very rare site and a few cases were described in pediatric patients ${ }^{[7]}$. It is generally caused by trauma (e.g., lip biting, sharp cusps, orthodontic appliances, self-in $\neg$ flicted injuries) that results in the rupture of excretory duct of minor salivary glands [8].

Khanna et al. affirmed that parafunctional habits, such as biting and sucking the lower lip, are also related to the higher incidence in this region ${ }^{[9]}$.

The clinical appearance of a mucus cyst is a distinct: fluctuant, painless swelling of the mucosa. About $75 \%$ of the lesions are smaller than $1 \mathrm{~cm}$ in diameter; however, rarely, the size can vary from few millimeters to several centimeters. Superficial lesions take on a bluish to translucent hue, whereas deep lesions have normal mucosal coloration and bleeding into the swelling may impart a bright red and vascular appearance ${ }^{[4]}$. The various differential diagnoses are ab $\neg$ scess, hematoma, fibroma, lipoma, hemangioma like this case, lymphangioma, salᄀivary neoplasms, recurrent herpes, mucous pemphigoid, benign and malignant tumors of salivary gland origin, varicose vein, irritation fibroma, oral lymph-epithelial cyst, gingival cyst of the adult. They are different by their clinical aspects and features ${ }^{[10]}$.

Bhargava et al. attested that histopathological examination is crucial to confirm the clinical diagnosis ${ }^{[5]}$. Extravasation mucoceles are usually resolve spontaneously, after surgical excision in some cases ${ }^{[11]}$.

There are no differences in the management of retention and extravasation mucoceles, and surgical removal is the standard method widely used for both. According to Romeo et al., surgical excision is the only treatment for this lesion, as constant reccurences in extravasation mucocele are observed when this procedure is not performed ${ }^{[2]}$. Baurmash proposed complete excision for small lesions and unroofing procedure (Remove the roof or covering of the cyst) for large mucoceles ${ }^{[6]}$. A strategy to prevent recurrences is to perform the excision of small lesions down to the muscular plane, with a margin of salivary gland tissue. In case of large lesions, marsupialization help prevent damage to vital structures, such as the labial branch of the mental nerve ${ }^{[2]}$. The excised tissue should be submitted to the pathological investigations to confirm the diagnosis. Laser ablation, cryosurgery, and electrocautery are approaches that have also been used for treatment of the conventional mucoceles, with variable success ${ }^{[4]}$. Another surgical method of oral mucocele management is ablation with $\mathrm{CO} 2$ laser, which decreases the chances of recurrence and complication and allows fast and simple lesion ablation. This procedure is also suitable for patients who cannot tolerate long procedures ${ }^{[2,8]}$. Steroid injection was also used in the non-surgical management of mucoceles ${ }^{[12]}$.

\section{Conclusion}

Oral mucocele is a fairly common lesion that primarily affects young patients and preferentially affects the lower lip. A mucus cyst on hard palate in old male patient is extremely rare. Extravasation mucocele is the most common subtype, affecting patients. Excision surgery is the most widely used treatment in able to avoid recurrences.

\section{Ethics approval and consent to participate}

Written informed consent was obtained from the patient to publish anonymized information in this article.

\section{Conflicts of Interest}

The authors declare that there is no conflict of interest regarding the publication of this paper. 


\section{Authors' contributions}

REG wrote the manuscript, BC read and corrected it. All authors read and approved the final manuscript.

\section{References}

[1] K.U. Nallasivam and B.R. Sudha. Oral mucocele: Review of literature and a case report. 2015 Aug; 7(Suppl 2): S731-S733.

[2] T.M.M. Bezerra, B.V.B. Monteiro, A.C.G. Henriques, M.V. Carvalho, C.F.W. Nonaka, M.C.C. Miguel. Epidemiological survey of mucus extravasation phenomenon at an oral pathology referral center during a 43 year period. Braz J Otorhinolaryngol. 2015.

[3] B. Senthilkumar, M.N. Mahabob. Mucocele: An unusual presentation of the minor salivary gland lesion. J Pharm Bioall Sci 2012;4:180-2.

[4] S. Titsinides, D. Kalyvas, K. Tosios. Mucocele of the dorsal surface of the tongue: A case report.2018. 10, 495-498.

[5] N. Bhargava, P. Agarwal, N. Sharma, M. Agrawal, M. Sidiq, P. Narain. An unusual presentation of oral mucocele in infant and its review. Case Rep Dent. vol.2014. ID 723130, P6.
[6] A.C. Chi, P.R. Lamberd, M.S. Richardson, B.W. Neville. Oral mucoceles: a clinocopathologic review of 1,824 cases, including unusual variants. J Oral Maxillofac Surg. 2011. 69(1), 86-93.

[7] M. Abdel-aziz, B. Khalifa, A. Nassar, A. Kamel, N. Naguid, A. El Tahan. Mucocele of the hard palate in children. Int. J. Pediatr. Otorhinolaryngol. 2016. 85, 4649.

[8] Ahad, A. Tandon, AK. Lamba, F. Faraz, P. Anand, A. Aleem. Diode laser assisted excision and low-level laser therapy in the management of mucus extravasation cysts: a case series. J Lasers Med Sci. 2017. 8(3), 155-159

[9] S. Khanna, N.N. Singh, G. Sreedhar, A. Purwar, S. Gupta. Oral mucous extravasation cyst: case series with comprehensive and systematic review on differential diagnosis. Int J Dent Case Rep. 2013. 3, 17-27.

[10] More CB, Bhavsar K, Varma S, Tailor M. Oral mucocele: a clinical and histopathological study. J Oral Maxillofac Pathol. 2014;18:S72-7.

[11] Ata-Ali J, Carrilo C, Bonet C, Balaguer J, Penarrocha M, M. Oral mucocele: review of the literature. J Clin Exp Dent. 2010;2:E18-21.

[12] Luiz AC, Hiraki KR, Lemos CA Jr, Hirota SK, Migliari DA. Treatment of painful and recurrent oral mucoceles with a high- potency topical corticosteroid: a case report. J Oral Maxillofac Surg. 2008;66:1737-9. 